\title{
Beta-Cell Function, Self-rated Health, and Lifestyle Habits in 64-Year-Old Swedish Women with Metabolically Healthy Obesity Phenotype
}

\author{
Ola Hjelmgren', Anders Gummesson², Göran Bergström ${ }^{1,2}$, Caroline Schmidt2,** \\ 'Department of Clinical Physiology, Institution of Neuroscience and Physiology and ${ }^{2}$ Department of Molecular and Clinical Medicine, Institution of Medicine, \\ Sahlgrenska Academy at Gothenburg University, Göteborg, Sweden
}

Background: A subset of obese individuals do not present metabolic abnormalities that commonly define the metabolic syndrome (MetS). This is referred to as a metabolically healthy obese (MHO) phenotype. The aim of the present study was to evaluate the prevalence of the $\mathrm{MHO}$ phenotype and its relationship with beta cell dysfunction by measuring C-peptide and proinsulin, anthropometric-, metabolic- and lipid appearance, as well as lifestyle behaviors and self-rated health in a cohort of 64-year-old Swedish women.

Methods: The National Cholesterol Education Program definition was used to assess MetS. We defined normal weight as body mass index (BMI) $18.5-24.9 \mathrm{~kg} / \mathrm{m}^{2}$ and obesity as $\mathrm{BMI} \geq 30 \mathrm{~kg} / \mathrm{m}^{2}$ to categorize participants as metabolically healthy normal weight, $\mathrm{MHO}$, and metabolically unhealthy obese.

Results: The MHO phenotype represented $36.3 \%$ of obese participants and $16.3 \%$ of total participants. The $\mathrm{MHO}$ group were at greater risk of having proinsulin levels $>11 \mathrm{pmol} / \mathrm{L}$, indicating impaired beta cell function. Further, homeostatic model assessment for insulin resistance, fasting plasma levels of insulin, and C-peptide showed significant trends, with the MHO phenotype group having intermediate levels among three groups. Health behaviors such as leisure time physical activity and alcohol intake were also intermediate in individuals with the $\mathrm{MHO}$ phenotype.

Conclusion: In this study, we demonstrate that over a third of the obese women in our sample were MHO. Further, women with the $\mathrm{MHO}$ phenotype showed intermediate profiles considering beta cell function and insulin resistance, as well as metabolic variables, and tended to rate their general health as worse than otherwise similar individuals of normal weight.

Key words: Metabolically benign obesity, Health, Life style
Received December 17, 2019

Reviewed February 8, 2020

Accepted February 29, 2020

*Corresponding author

Caroline Schmidt

(i)

https://orcid.org/0000-0001-8534-3237

Department of Molecular and Clinical Medicine, Institution of Medicine, Sahlgrenska Academy at Gothenburg University, 41345 Göteborg, Sweden Tel: +46-31-342-9696

E-mail: caroline.schmidt@wlab.gu.se

\section{INTRODUCTION}

Obesity is a complex, heterogeneous condition with significant phenotypic variation. ${ }^{1}$ Whereas obesity is closely related to clustering of metabolic risk factors and increased morbidity and mortality, a subset of obese individuals do not present with metabolic abnormalities. This phenotype is considered metabolically healthy obese (MHO). ${ }^{2,3}$ Why these individuals do not develop metabolic syn- drome (MetS) is currently unknown. ${ }^{4}$ However, lifestyle behaviors, such as physical activity and sedentary time, may differ between $\mathrm{MHO}$ and metabolically unhealthy obese (MUO) phenotypes. Previous studies have shown inconsistent results comparing physical activity levels between MHO and MUO subjects, with some studies reporting significant differences while other studies do not. ${ }^{1}$ Further, self-rated health (SRH), an inclusive measure of health, has previously been shown to be associated with increased risk of

Copyright (C) 2020 Korean Society for the Study of Obesity

(a) This is an Open Access article distributed under the terms of the Creative Commons Attribution Non-Commercial License (https://creativecommons.org/licenses/by-nc/4.o/) which permits unrestricted non-commercial use, distribution, and reproduction in any medium, provided the original work is properly cited. 
progression to an unhealthy metabolic status in metabolically healthy individuals. ${ }^{5}$ Previous studies have also shown that low $\mathrm{SRH}$ is associated with increased incidence of both insulin resistance and type 2 diabetes mellitus. ${ }^{6,7}$ However, preserved insulin sensitivity and paucity of the components of the MetS may characterize the $\mathrm{MHO}$ phenotype. ${ }^{8}$ Physiologically, virtually all proinsulin molecules are cleaved into insulin and C-peptide. In healthy subjects, only a minor percentage of un-cleaved intact proinsulin is released into the circulation. However, insulin resistance leads to an increased demand for insulin, and thus the cleavage capacity of the processing enzymes may be exhausted, and proinsulin and C-peptide may be increased. ${ }^{9}$ Further, insulin resistance may cause metabolic modifications that lead to imbalance in glucose metabolism, causing chronic hyperglycemia, which in turn initiates oxidative stress and inflammatory response that leads to cell damage. ${ }^{10}$ Insulin resistance can also change systemic lipid metabolism, which leads to the development of dyslipidemia and the well-known pattern of high levels of plasma triglycerides, low levels of high-density lipoprotein, and appearance of small dense low-density lipoprotein. ${ }^{10}$ Therefore, measurements of intact proinsulin are important indirect predictors for insulin resistance and play roles as direct biomarkers of beta cell dysfunction. ${ }^{9}$

The aim of the present study was to evaluate the prevalence of the MHO phenotype and its relationships with anthropometric-, metabolic- and lipid appearance, as well as lifestyle behaviors and $\mathrm{SRH}$, in a cohort of 64-year-old Swedish women. A further aim was to explore beta cell dysfunction by measuring C-peptide and proinsulin in the $\mathrm{MHO}$ phenotype.

\section{METHODS}

\section{Study population and design}

All participants received both written and oral information before they gave consent to take part in the study. The Ethics Committee at Sahlgrenska University Hospital approved the protocol (Dnr: S 286-01).

The study population and study design have previously been extensively described elsewhere. ${ }^{8}$ In brief, all 64-year-old women $(n=4,856)$ identified through the County Register in Gothenburg, Sweden, were sent an invitation letter to participate in a screening examination. Those who accepted $(n=2,893)$ completed a brief questionnaire that was enclosed with the letter. Exclusion criteria were cancer (unless no relapse during the last 5 years), chronic inflammatory disease, severe mental disorder, other severe illness, drug addiction, or inability to understand Swedish $(n=298)$.

Participants were invited to a screening examination including an oral glucose tolerance test (OGTT). The OGTT procedure has previously been thoroughly described. ${ }^{11}$ The World Health Organization (WHO) criteria for capillary blood glucose values for cutoff were used. ${ }^{12}$ No OGTTs were performed on subjects with known diabetes. The examinations included a questionnaire soliciting information regarding previous diseases, current medication, smoking habits, heredity for diabetes, TV time, leisure time physical activity (LTPA) and SRH. Anthropometric measurements were performed, and blood pressure and heart rate were recorded. Body weight was measured in light clothing. Waist and hip circumferences were measured according to current guidelines. ${ }^{12}$ Finally, 639 women were included in the study.

\section{Definition of the phenotype groups}

The National Cholesterol Education Program definition was used to assess MetS (Supplementary Table 1$).{ }^{13}$ By defining normal weight as body mass index (BMI) $18.5-24.9 \mathrm{~kg} / \mathrm{m}^{2}$ and obesity as BMI $\geq 30 \mathrm{~kg} / \mathrm{m}^{2},{ }^{14}$ the participants were categorized as (1) metabolically healthy normal weight (MHNW; $\mathrm{n}=180)$, (2) metabolically healthy obese ( $\mathrm{MHO} ; \mathrm{n}=53)$, and (3) metabolically unhealthy obese (MUO; $n=93$ ) (Supplementary Table 2). This resulted in a sample of 326 women (Supplementary Fig. 1). The remaining 313 women were categorized as metabolic abnormal, normal weight, metabolic healthy, overweight, or metabolic abnormal, overweight.

\section{Biochemical analysis}

The biochemical analyses we performed have been described in detail elsewhere. ${ }^{15,16}$ All analyses were performed at the Wallenberg Laboratory for Cardiovascular Research, Sahlgrenska University Hospital, Gothenburg, Sweden.

\section{Assessment of SRH}

SRH was assessed by the question "In general, how would you rate your health?” Answers were dichotomized into two groups, 
good health (excellent and good) and average health or less (average, poor and very poor) based on previous studies. ${ }^{17,18} \mathrm{SRH}$ was further assessed by the question "In general, how would you rate your health compared to others your age?” with answers divided into three categories, better (much better and better), neither better nor worse, and worse (worse and much worse).

\section{Statistics}

The IBM SPSS version 22.0 (IBM Corp., Armonk, NY, USA) was used for all statistical analyses. Normally distributed continuous data are presented as the mean \pm standard deviation (SD). Skewed data are presented as the median and range and nominal data are presented as number and percent. Comparisons between groups were analyzed by one-way analysis of variance with the least significant difference post-hoc test. In addition, one-way test was used for analyzing trends between groups. Trend analyses in nonparametric variables were performed with Jonckheere-Terpstra test. Analyses of nominal data were performed with chi-square tests. The $P$-values $<0.05$ were considered statistically significant.

\section{RESULTS}

In the sample of 326 women, $71.5 \%$ were metabolically healthy and $44.8 \%$ were obese. The MHO phenotype represented $36.3 \%$ of obese participants and $16.3 \%$ of participants in the total sample. The mean age was 64.5 years $(\mathrm{SD}, 0.3)$. Values for baseline anthropometrics and lifestyle behaviors, baseline metabolic factors, including insulin variables, and lipids are presented in Tables 1 and 2, respectively. Briefly, the majority of the variables showed significant trends, with the $\mathrm{MHO}$ phenotype group having intermediate levels and the MUO phenotype group having levels that were the most unfavorable. The MHO group had significantly increased BMI, weight, waist circumference, and blood pressure, compared to the MHNW group. Further, fasting plasma insulin levels, plasma proinsulin, C-peptide, triglycerides, apolipoprotein B levels, and apolipoprotein B to A-I ratio were significantly increased, while highdensity lipoprotein cholesterol was significantly lower in the $\mathrm{MHO}$ group than in the MHNW group. However, total cholesterol did not differ between the phenotype groups, nor did low-density lipoprotein cholesterol.

Fasting plasma levels of insulin, proinsulin, and C-peptide showed significant trends with the $\mathrm{MHO}$ phenotype group having intermediate levels and the MUO phenotype group having the highest levels. Proinsulin levels $>11 \mathrm{pmol} / \mathrm{L}$ indicating beta-cell dysfunction, was most common in the MUO group (30\%). In the MHO group, the corresponding figure was $9.8 \%$, while only one patient $(0.6 \%)$ in the MHNW group had proinsulin levels above $11 \mathrm{pmol} / \mathrm{L}$. The risk ratio was 18.2 (95\% confidence interval, 2.1 to 159.3 ) for increased

Table 1. Baseline anthropometric values and life style behaviors of the study participants according to phenotype

\begin{tabular}{|c|c|c|c|c|}
\hline Variable & $\begin{array}{l}\text { Metabolically healthy } \\
\text { normal weight }(n=180)\end{array}$ & $\begin{array}{l}\text { Metabolically healthy obese } \\
\qquad(n=53)\end{array}$ & $\begin{array}{c}\text { Metabolically unhealthy } \\
\text { obese }(n=93)\end{array}$ & $P$ for trend \\
\hline $\mathrm{BMI}\left(\mathrm{kg} / \mathrm{m}^{2}\right)$ & $22.9 \pm 1.5$ & $33.2 \pm 3.2^{\ddagger}$ & $34.3 \pm 3.4^{\ddagger}, \S$ & $<0.001$ \\
\hline Weight $(\mathrm{kg})$ & $61.8 \pm 5.8$ & $89.3 \pm 10.1^{\ddagger}$ & $91.2 \pm 10.3^{\dagger}$ & $<0.001$ \\
\hline Waist circumference (cm) & $81 \pm 5$ & $104 \pm 8^{\ddagger}$ & $109 \pm 10^{ \pm, n}$ & $<0.001$ \\
\hline Systolic blood pressure (mmHg) & $135 \pm 19$ & $138 \pm 18^{\dagger}$ & $147 \pm 17^{ \pm . \|}$ & $<0.001$ \\
\hline Diastolic blood pressure (mmHg) & $75 \pm 6$ & $78 \pm 9^{*}$ & $83 \pm 8^{\ddagger, \S}$ & $<0.001$ \\
\hline LTPA at least 30 minutes $1-2$ times/wk breaking sweat & $75(41.7)$ & $21(39.6)$ & $27(29.0)^{*}$ & 0.005 \\
\hline Lost $\geq 5 \mathrm{~kg}$ in weight on purpose in less than 1 year & $70(38.9)$ & $41(77.4)^{\ddagger}$ & $79(84.9)^{\ddagger}$ & $<0.001$ \\
\hline TV time $\geq 3-6$ hours/day & $25(13.9)$ & $7(13.2)$ & $22(23.7)$ & 0.173 \\
\hline Smoking-cigarette years & $14.3(0.4-75.3)$ & $22.5(0.3-56.0)$ & $21.6(1.3-92.0)$ & 0.021 \\
\hline Alcohol intake/day (g) & $8.9(0.0-36.3)$ & $5.0(0.0-46.3)$ & $2.7(0.0-38.2)^{\dagger}$ & 0.006 \\
\hline Lipid medication & $15(8.3)$ & $4(7.5)$ & $24(25.8)^{\ddagger}, \|$ & $<0.001$ \\
\hline Hypertensive medication & $34(18.9)$ & $17(32.1)^{*}$ & $54(53.8)^{\ddagger . \|}$ & $<0.001$ \\
\hline
\end{tabular}

Values are presented as mean \pm standard deviation, number $(\%)$, or median (range).

${ }^{*} P<0.05$ vs. metabolically healthy normal weight; ${ }^{\dagger} P<0.01$ vs. metabolically healthy normal weight; ${ }^{\ddagger} P<0.001$ vs. metabolically healthy normal weight; ${ }^{\S} P<0.05$ vs. metabolically healthy obese; $\| P<0.01$ vs. metabolically healthy obese; ${ }^{"} P<0.001$ vs. metabolically healthy obese.

$\mathrm{BMI}$, body mass index; LTPA, leisure time physical activity. 
Table 2. Baseline metabolic and insulin factors for the study participants according to phenotype

\begin{tabular}{|c|c|c|c|c|}
\hline Variable & $\begin{array}{c}\text { Metabolically healthy normal } \\
\text { weight }(n=180)\end{array}$ & $\begin{array}{l}\text { Metabolically healthy obese } \\
\qquad(n=53)\end{array}$ & $\begin{array}{l}\text { Metabolically unhealthy obese } \\
\qquad(\mathrm{n}=93)\end{array}$ & $P$ for trend \\
\hline Fasting plasma glucose (mmol/L) & $5.3 \pm 1.8$ & $5.1 \pm 1.04$ & $6.9 \pm 2.5^{t, 9}$ & $<0.001$ \\
\hline Fasting plasma insulin (pmol/L) & $40.5 \pm 47.1$ & $61.9 \pm 35.4^{\ddagger}$ & $114.2 \pm 91.4^{ \pm .,}$ & $<0.001$ \\
\hline Plasma pro-insulin (pmol/L) & $3.1 \pm 2.0$ & $5.9 \pm 4.8^{\ddagger}$ & $11.5 \pm 12.4^{\ddagger} \|$ & $<0.001$ \\
\hline C-peptide (nmol/L) & $174 \pm 67$ & $259 \pm 101^{\ddagger}$ & $366 \pm 165^{\ddagger, \pi}$ & $<0.001$ \\
\hline Insulin resistance (HOMA-IR) & $1.61 \pm 3.26$ & $2.10 \pm 1.37^{\ddagger}$ & $5.75 \pm 3.39^{\mp .1}$ & $<0.001$ \\
\hline Total cholesterol (mmol/L) & $5.90 \pm 1.09$ & $5.97 \pm 0.84$ & $5.71 \pm 1.16$ & 0.215 \\
\hline LDL cholesterol (mmol/L) & $3.53 \pm 0.98$ & $3.76 \pm 0.86$ & $3.46 \pm 0.99$ & 0.729 \\
\hline HDL cholesterol (mmol/L) & $1.84 \pm 0.41$ & $1.62 \pm 0.37^{\ddagger}$ & $1.27 \pm 0.30^{\ddagger} .9$ & $<0.001$ \\
\hline Triglycerides (mmol/L) & $1.08(0.5-3.0)$ & $1.27(0.6-2.6)^{\dagger}$ & $1.97(0.7-5.9)^{\ddagger .7}$ & $<0.001$ \\
\hline $\mathrm{apoB}(\mathrm{mmol} / \mathrm{L})$ & $1.07 \pm 0.25$ & $1.14 \pm 0.20^{*}$ & $1.25 \pm 0.31^{ \pm \S}$ & $<0.001$ \\
\hline apoA-I (mmol/L) & $1.64 \pm 0.27$ & $1.60 \pm 0.28$ & $1.44 \pm 0.22^{\ddagger}, \Omega$ & $<0.001$ \\
\hline apoB to apoA-I ratio & $0.66 \pm 0.17$ & $0.73 \pm 0.19^{\dagger}$ & $0.88 \pm 0.22^{\ddagger ., 1}$ & $<0.001$ \\
\hline Ox-LDL (U/L) & $56.0 \pm 18.2$ & $58.7 \pm 16.1$ & $60.4 \pm 16.6^{*}$ & 0.041 \\
\hline hsCRP (nmol/L) & $17.8(0.3-720.6)$ & $39.6(2.4-192.7)^{\ddagger}$ & $36.2(3.0-204.6)^{\ddagger}$ & $<0.001$ \\
\hline
\end{tabular}

Values are presented as mean \pm standard deviation deviation, number (\%), or median (range).

${ }^{*} P<0.05$ vs. metabolically healthy normal weight; ${ }^{\dagger} P<0.01$ vs. metabolically healthy normal weight; ${ }^{\ddagger} P<0.001$ vs. metabolically healthy normal weight; ${ }^{\S} P<0.05$ vs. metabolically healthy obese; $" P<0.01$ vs. metabolically healthy obese; ${ }^{"} P<0.001$ vs. metabolically healthy obese.

HOMA-IR, homeostatic model assessment for insulin resistance; LDL, low-density lipoprotein; HDL, high-density lipoprotein; apoB, apolipoprotein B; apoA-I, apolipoprotein A-l; OxLDL, oxidized low-density lipoprotein; hsCRP, high-sensitive C-reaction protein.

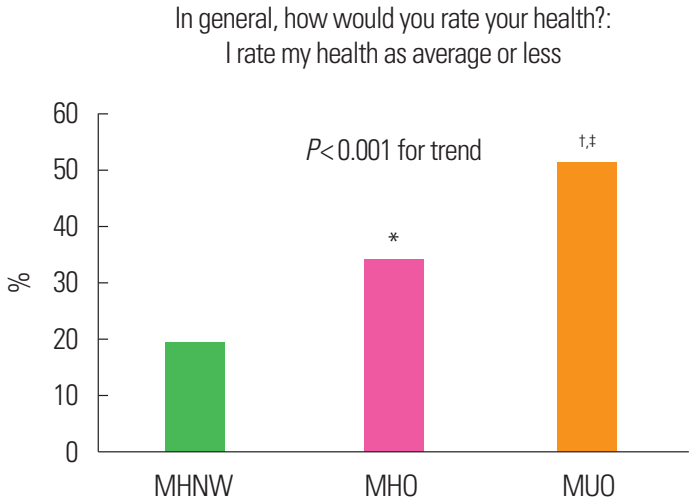

Figure 1. Proportion of each phenotype group rating their health as average or worse. ${ }^{*} P<0.001$ vs. MHNW; ${ }^{\dagger} P<0.01$ vs. MHNW; ${ }^{\ddagger} P<0.05$ vs. MHO. MHNW, metabolically healthy normal weight; $\mathrm{MHO}$, metabolically healthy obese; MUO, metabolically unhealthy obese.

risk among MHO subjects to have a proinsulin level $>11 \mathrm{pmol} / \mathrm{L}$ compared to MHNW subjects. Insulin resistance assessed as homeostatic model assessment for insulin resistance (HOMA-IR) significantly differed between the $\mathrm{MHO}$ and the MHNW groups. Further, the MUO group had significantly higher values of HOMA-IR compared to both other groups.

Both obese phenotype groups were more likely to have lost $\geq 5$ $\mathrm{kg}$ in weight on purpose in less than one year compared to the normal weight group. LTPA showed a significant trend towards less

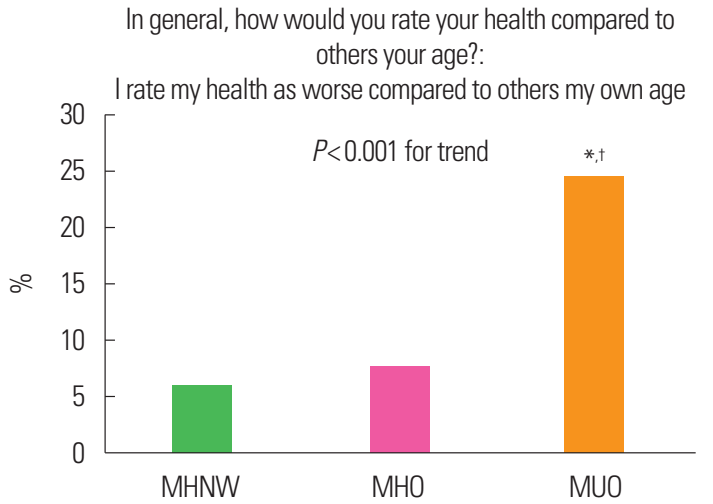

Figure 2. Proportion of each phenotype group rating their health as worse compared to others their own age. ${ }^{*} P<0.01$ vs. MHNW; ${ }^{\dagger} P<0.01$ vs. MHO. MHNW, metabolically healthy, normal weight; $\mathrm{MHO}$, metabolically healthy obese; MUO, metabolically unhealthy obese.

activity in the MUO group, with the MHNW group reporting the most activity. However, no difference was observed in the number of subjects performing LTPA at least 30 minutes 1-2 times per week while breaking sweat between the MHO and the MHNW groups, but this variable differed significantly between the MUO and MHNW groups. No difference between phenotype groups was observed for TV time $\geq 3-6$ hours per day. The MUO group reported significantly more cigarette years, representing smoking habits, compared to the normal weight group. 
SRH showed a significant trend with the $\mathrm{MHO}$ as the intermediate group and the MUO group having the most subjects who rated their general health as average. A similar trend was observed for rating health worse than that of others their own age. A significant difference was observed between the MHO group and the MHNW group, with more subjects rating their general health as average among those with $\mathrm{MHO}$. No difference was observed between the $\mathrm{MHO}$ and the MHNW groups in rating their health to be worse than others their own age, while a greater number of individuals in the MUO group rated their health worse than others their own age when compared to the MHNW and MHO groups (Figs. 1 and 2).

\section{DISCUSSION}

The results from this sample of 64-year-old women showed that one-third of the obese participants were of $\mathrm{MHO}$ phenotype. Compared with the prevalence of $\mathrm{MHO}$ in cohorts comprising The Healthy Obese Project sample, ${ }^{19}$ the prevalence reported in the present study is higher. One previous study found that the prevalence of $\mathrm{MHO}$ ranges between $12 \%$ and nearly $60 \%$ in women, depending on the definition used. ${ }^{20}$ However, the criteria used for the definitions of $\mathrm{MHO}$ in that study did not include exactly the same criteria used in the present study.

An interesting observation in this study is that the $\mathrm{MHO}$ group rated their health as similar to others their own age, like the MHNW group, while a significant difference in general health was observed between these groups. Previously, SRH was suggested to be an independent risk factor of metabolic abnormalities, and studies have shown that SRH is low in people with MetS and obesity. ${ }^{5}$ An earlier study of 40-year-old Finnish males showed that those with BMI $\geq 30 \mathrm{~kg} / \mathrm{m}^{2}$ rated their health worse than men who were of normal weight. ${ }^{18}$ This finding is in line with that of the present study in a sample of women. Further, the MUO group reported significantly worse results for SRH compared to the other phenotype groups. A recent study showed low SRH to be independently associated with the risk of progression to metabolically unhealthy status in metabolically healthy individuals, especially in those with obesity. ${ }^{5}$

Physical activity is known to be associated with health-related benefits leading to, for instance, lower risk of obesity and diabetes. $^{21,22}$ In the present study, the proportion of subjects performing
LTPA for at least 30 minutes $\geq 1-2$ times per week while breaking sweat was similar across phenotype groups, nor were there differences between obese groups. A previous study revealed no difference between $\mathrm{MHO}$ subjects and non-MHO subjects in terms of moderate-to-vigorous activity in a group of 45- to 85-year-old individuals. ${ }^{23}$ Further, another previous study showed that MHO subjects spent more time stepping/day and less time being sedentary compared to MUO subjects, while there was no difference in sedentary time/day or total stepping time/day between $\mathrm{MHO}$ and MHNW subjects. ${ }^{24}$ Previous studies utilized TV viewing time as a proxy measure to assess sedentary behavior in $\mathrm{MHO}$ and $\mathrm{MUO}$ individuals. ${ }^{1}$ In the present study, we found no difference in TV time, consistent with previous studies. ${ }^{25,26}$ The lack of difference in physical activity and TV time between the obese phenotype groups may be due to the small groups included in our study.

MHO individuals may have higher inflammatory markers when compared with metabolically healthy non-obese subjects, and it is suggested that this intermediate inflammatory status put them at delayed risk of metabolic disorders. ${ }^{27}$ In our study, differences in both waist circumference and C-reactive protein were observed between $\mathrm{MHO}$ and MHNW subjects, while only waist circumference differed between the $\mathrm{MHO}$ and MUO phenotypes.

Proinsulin is the precursor form of insulin, and is synthesized, processed, and cleaved to form mature insulin and C-peptide. Glucose intolerant and/or insulin resistant individuals have increased concentrations of proinsulin. ${ }^{28}$ In the present study, MHO participants had increased levels of plasma proinsulin, split proinsulin, and C-peptide compared to MHNW participants, but decreased values compared to MUO participants. Plasma proinsulin levels $>11 \mathrm{pmol} / \mathrm{L}$ were increased and considered indicative of beta cell dysfunction in a previous study. ${ }^{10}$ In the present study, MHO participants had a significantly increased plasma proinsulin value of $5.9 \mathrm{pmol} / \mathrm{L}$ compared to MHNW participants, who had an average of $3.1 \mathrm{pmol} / \mathrm{L}$, while MUO participants showed a significantly increased value of $11.5 \mathrm{pmol} / \mathrm{L}$. In addition, proinsulin values $>11$ $\mathrm{pmol} / \mathrm{L}$ were significantly less common in the MHO group compared to the MUO group. This suggests that the MHO participants in our study are in earlier phases of metabolic disease, while the MUO participants had already developed beta cell dysfunction.

Previously, C-peptide was shown to be associated with decreased 
levels of high-density lipoprotein. ${ }^{29}$ We observed that C-peptide levels were highest in the MUO group, that the MHNW group had the lowest levels, and the $\mathrm{MHO}$ group showed intermediate levels, while high-density lipoprotein cholesterol showed an inverse trend with the lowest level in the MUO group. A similar pattern was observed by our research group in a cohort of initially healthy 58-yearold men (not published). Further, in the present study showed the MHO subjects were more insulin sensitive than the MUO subjects, a finding that agrees with those of previous studies. ${ }^{30}$

Insulin resistance assessed by HOMA-IR previously indicated that worse metabolic conditions are associated with higher risk of increased HOMA index. ${ }^{31}$ This is in line with the findings of the present study, in which there was a trend toward increased HOMA index with worsening metabolic condition, with the MUO group having the highest levels and the MHO group having intermediate values. Compared to the MHNW group, both obese groups had significantly increased HOMA values, which also agrees with the results of previous studies. ${ }^{31}$

There are limitations as well as strengths of the present study that need to be considered. Women of the same age with different degrees of insulin sensitivity and obesity were included in our sample, and those with prevalent cardiovascular disease and those who had received cardiovascular disease medication were excluded. This approach has the disadvantage that the cohort is less representative of the general population, and it may have affected the number of MUO participants we included. Therefore, we may have overestimated the prevalence of $\mathrm{MHO}$ in the obese population. On the other hand, the participants were selected in a structured way among a representative, homogenous population sample, and confounding factors such as age, sex, and concomitant cardiovascular disease were constant at baseline. To define obesity using BMI is another limitation because it does not differentiate between body lean mass and body fat mass, and a person can have a high BMI but still have a very low fat mass. ${ }^{32}$ Waist circumference has been shown to be a more specific measure of visceral obesity. ${ }^{33}$ Further, results from the Framingham study showed that being underweight is associated with increased risk of non-cardiovascular mortality. ${ }^{24}$ In our study, we included normal weight participants with BMI 18.5$24.9 \mathrm{~kg} / \mathrm{m}^{2}$, as previously suggested by $\mathrm{WHO},{ }^{34}$ with the intention of excluding underweight participants and avoiding underestimat- ing body weight in the normal weight group.

In conclusion, this cross-sectional study detected an $\mathrm{MHO}$ prevalence of nearly $40 \%$ among a homogeneous sample of obese 64-year-old women, and found that women with MHO phenotype have an intermediate profile for variables measuring beta cell function and HOMA index, as well as for anthropometric and metabolic variables. Further, women in the MHO group rated their general health as worse compared to those with normal weight. This emphasizes the question of whether MHO individuals, defined by having few MetS features, actually are healthy.

\section{CONFLICTS OF INTEREST}

The authors declare no conflict of interest.

\section{ACKNOWLEDGMENTS}

Grants from the Swedish Heart-Lung Foundation, the Swedish Medical Research Council (12270 and 10880), and AstraZeneca, Mölndal, Sweden, supported this work.

The authors would like to thank the staff of the Cardiometabolic Clinical Research Group at the Wallenberg Laboratory for Cardiovascular Research for technical assistance: Marie Louise Ekholm, Carita Fagerlund, Magdalena Göthberg, Birgitta Jannemark, Marie Jonasson, Pia Lindén, and Ulrica Prahl Gullberg.

\section{AUTHOR CONTRIBUTIONS}

Study concept and design: GB; acquisition of data: GB; analysis and interpretation of data: CS; drafting of the manuscript: CS and AG; critical revision of the manuscript: $\mathrm{GB}$ and $\mathrm{OH}$; statistical analysis: CS; obtained funding: GB; administrative, technical, or material support: CS; and study supervision: GB.

\section{SUPPLEMENTARY MATERIALS}

Supplementary Tables 1, 2 and Supplementary Figure 1 can be found via https://doi.org/10.7570/jomes19078. 


\section{REFERENCES}

1. Camhi SM, Crouter SE, Hayman LL, Must A, Lichtenstein AH. Lifestyle Behaviors in metabolically healthy and unhealthy overweight and obese women: a preliminary study. PLoS One 2015; 10:e0138548.

2. Truthmann J, Mensink GB, Bosy-Westphal A, Scheidt-Nave C, Schienkiewitz A. Metabolic health in relation to body size: changes in prevalence over time between 1997-99 and 2008-11 in Germany. PLoS One 2016;11:e0167159.

3. Goday A, Calvo E, Vázquez LA, Caveda E, Margallo T, Catalina-Romero C, et al. Prevalence and clinical characteristics of metabolically healthy obese individuals and other obese/nonobese metabolic phenotypes in a working population: results from the Icaria study. BMC Public Health 2016;16:248.

4. Korhonen PE, Korsoff P, Vahlberg T, Kaaja R. Lifestyle of metabolically healthy obese individuals. Prim Care Diabetes 2015;9:179-83.

5. Kim MH, Chang Y, Jung HS, Shin H, Ryu S. Impact of selfrated health on progression to a metabolically unhealthy phenotype in metabolically healthy obese and non-obese individuals. J Clin Med 2019;8:E34.

6. Andersson S, Ekman I, Friberg F, Daka B, Lindblad U, Larsson CA. The association between self-rated health and impaired glucose tolerance in Swedish adults: a cross-sectional study. Scand J Prim Health Care 2013;31:111-8.

7. Tapp RJ, O’Neil A, Shaw JE, Zimmet PZ, Oldenburg BF; AusDiab Study Group. Is there a link between components of healthrelated functioning and incident impaired glucose metabolism and type 2 diabetes? The Australian Diabetes Obesity and Lifestyle (AusDiab) study. Diabetes Care 2010;33:757-62.

8. Owei I, Umekwe N, Provo C, Wan J, Dagogo-Jack S. Insulinsensitive and insulin-resistant obese and non-obese phenotypes: role in prediction of incident pre-diabetes in a longitudinal biracial cohort. BMJ Open Diabetes Res Care 2017;5:e000415.

9. Pfützner A, Forst T. Elevated intact proinsulin levels are indicative of Beta-cell dysfunction, insulin resistance, and cardiovascular risk: impact of the antidiabetic agent pioglitazone. J Diabetes Sci Technol 2011;5:784-93.

10. Ormazabal V, Nair S, Elfeky O, Aguayo C, Salomon C, Zuñiga
FA. Association between insulin resistance and the development of cardiovascular disease. Cardiovasc Diabetol 2018;17:122.

11. Brohall G, Behre CJ, Hulthe J, Wikstrand J, Fagerberg B. Prevalence of diabetes and impaired glucose tolerance in 64-year-old Swedish women: experiences of using repeated oral glucose tolerance tests. Diabetes Care 2006;29:363-7.

12. World Health Organization. Definition, diagnosis and classification of diabetes mellitus and its complications: report of WHO consultation. Part 1: diagnosis and classification of diabetes mellitus. Geneva: World Health Organization; 1999.

13. National Cholesterol Education Program (NCEP) Expert Panel on Detection, Evaluation, and Treatment of High Blood Cholesterol in Adults (Adult Treatment Panel III). Third report of the national cholesterol education program (NCEP) expert panel on detection, evaluation, and treatment of high blood cholesterol in adults (Adult Treatment Panel III) final report. Circulation 2002;106:3143-421.

14. Malik S, Wong ND, Franklin SS, Kamath TV, L'Italien GJ, Pio $\mathrm{JR}$, et al. Impact of the metabolic syndrome on mortality from coronary heart disease, cardiovascular disease, and all causes in United States adults. Circulation 2004;110:1245-50.

15. Englund Ogge L, Brohall G, Behre CJ, Schmidt C, Fagerberg B. Alcohol consumption in relation to metabolic regulation, inflammation, and adiponectin in 64-year-old Caucasian women: a population-based study with a focus on impaired glucose regulation. Diabetes Care 2006;29:908-13.

16. Schmidt C, Fagerberg B. ApoB/apoA-I ratio is related to femoral artery plaques in 64-year-old women also in cases with low LDL cholesterol. Atherosclerosis 2008;196:817-22.

17. Kivimäki M, Head J, Ferrie JE, Hemingway H, Shipley MJ, Vahtera J, et al. Working while ill as a risk factor for serious coronary events: the Whitehall II study. Am J Public Health 2005;95:98-102.

18. Näslindh-Ylispangar A, Sihvonen M, Vanhanen H, Kekki P. Self-rated health and risk factors for metabolic syndrome among middle-aged men. Public Health Nurs 2005;22:515-22.

19. van Vliet-Ostaptchouk JV, Nuotio ML, Slagter SN, Doiron D, Fischer K, Foco L, et al. The prevalence of metabolic syndrome and metabolically healthy obesity in Europe: a collaborative analysis of ten large cohort studies. BMC Endocr Disord 2014; 
14:9.

20. Velho S, Paccaud F, Waeber G, Vollenweider P, Marques-Vidal P. Metabolically healthy obesity: different prevalences using different criteria. Eur J Clin Nutr 2010;64:1043-51.

21. Ekelund U, Besson H, Luan J, May AM, Sharp SJ, Brage S, et al. Physical activity and gain in abdominal adiposity and body weight: prospective cohort study in 288,498 men and women. Am J Clin Nutr 2011;93:826-35.

22. Tuomilehto J, Lindström J, Eriksson JG, Valle TT, Hämäläinen $\mathrm{H}$, Ilanne-Parikka $\mathrm{P}$, et al. Prevention of type 2 diabetes mellitus by changes in lifestyle among subjects with impaired glucose tolerance. N Engl J Med 2001;344:1343-50.

23. de Winter M, Rioux BV, Boudreau JG, Bouchard DR, Sénéchal M. Physical activity and sedentary patterns among metabolically healthy individuals living with obesity. J Diabetes Res 2018;2018:7496768.

24. de Rooij BH, van der Berg JD, van der Kallen CJ, Schram MT, Savelberg HH, Schaper NC, et al. Physical activity and sedentary behavior in metabolically healthy versus unhealthy obese and non-obese individuals: the Maastricht study. PLoS One 2016;11:e0154358.

25. Hankinson AL, Daviglus ML, Van Horn L, Chan Q, Brown I, Holmes E, et al. Diet composition and activity level of at risk and metabolically healthy obese American adults. Obesity (Silver Spring) 2013;21:637-43.

26. Bell JA, Kivimaki M, Batty GD, Hamer M. Metabolically healthy obesity: what is the role of sedentary behaviour? Prev Med 2014;62:35-7.

27. Wildman RP, Kaplan R, Manson JE, Rajkovic A, Connelly SA, Mackey RH, et al. Body size phenotypes and inflammation in the Women's Health Initiative Observational Study. Obesity (Silver Spring) 2011;19:1482-91.

28. Vangipurapu J, Stančáková A, Kuulasmaa T, Kuusisto J, Laakso M. Both fasting and glucose-stimulated proinsulin levels predict hyperglycemia and incident type 2 diabetes: a population-based study of 9,396 Finnish men. PLoS One 2015;10:e0124028.

29. Banu S, Jabir NR, Manjunath CN, Shakil S, Kamal MA. Cpeptide and its correlation to parameters of insulin resistance in the metabolic syndrome. CNS Neurol Disord Drug Targets 2011;10:921-7.

30. Dhana K, Koolhaas CM, van Rossum EF, Ikram MA, Hofman A, Kavousi M, et al. Metabolically healthy obesity and the risk of cardiovascular disease in the elderly population. PLoS One 2016;11:e0154273.

31. Iglesias Molli AE, Penas Steinhardt A, López AP, González CD, Vilariño J, Frechtel GD, et al. Metabolically healthy obese individuals present similar chronic inflammation level but less insulin-resistance than obese individuals with metabolic syndrome. PLoS One 2017;12:e0190528.

32. Nuttall FQ. Body mass index: obesity, BMI, and health: a critical review. Nutr Today 2015;50:117-28.

33. Bhurosy T, Jeewon R. Pitfalls of using body mass index (BMI) in assessment of obesity risk. Curr Res Nutr Food Sci 2013;1: 71-6.

34. Pencina M, DÁgostino RB, Fox CS, Vasan RS, Kannel WB. Obesity is independently associated with long-term risk of cardiovascular mortality and underweight with risk of non-cardiovascular mortality in Framingham offspring cohort [abstract]. Circulation 2009;120:S508. 